\title{
Involving Users and Creating Symbols for Tangible Programming: a Case Study with TaPrEC
}

Original Title: Envolvendo Usuários e Criando Símbolos para Programação Tangível: um Estudo de Caso com TaPrEC

\author{
Marleny Luque Carbajal', M. Cecília C. Baranauskas' \\ ${ }^{1}$ Instituto de Computação, Universidade Estadual de Campinas (UNICAMP) - Campinas, SP - Brasil
}

\begin{tabular}{l}
\hline ARTICLE INFO \\
\hline Article history: \\
Received 11 February 2019 \\
Accepted 07 April 2020 \\
Available online 05 May 2020 \\
\hline \\
Keywords: \\
Participatory Design \\
Tangible Programming \\
BrainDraw \\
Programming Learning \\
\hline
\end{tabular}

ISSN: $2595-9077$

DOI: JCThink.2019.v3.n1.p65

\begin{abstract}
INTRODUCTION: Participatory Design is an approach that is characterized by the active participation of users as part of the design team, thus reflecting their perspectives and needs in the product design. BrainDraw is a participatory technique for use in the design phase of product creation. This article investigates the use of participatory practices with elementary school teachers, aiming at the redesign of the programming blocks of TaPrEC, a tangible programming environment for children. OBJECTIVE: This work aimed at the redesign of symbols for the repetition blocks of TaPrEC involving the main stakeholders. METHOD: A Case Study in an educational space that offers activities during out-of-school hours to children was carried out using the BrainDraw technique with a group of elementary school teachers to redesign the symbols of the repetition blocks of the TaPrEC. The experimentation and evaluation of the created symbols were carried out by the same teachers and a group of elementary school children. We also applied the Self-Assessment Manikin form to assess the participants' affective responses during participatory activities. RESULTS: The results of the workshops highlight that the symbols created by the teachers have been better accepted by teachers and children. This positive acceptance may result from the fact that the participatory solutions proposed by the acceptance may result from the fact that the participatory solutions proposed by the
teachers suggest associations with everyday elements such as traffic signs and the teachers suggest associations with everyday elements such as trafic signs and the
symbol of multiplication. CONCLUSION: Participatory Design is a process that involves researchers and end-users in creating products for their use. Using this approach, we studied different symbol proposals for representing and understanding the repetition blocks of TaPrEC, a tangible programming environment, to promote a solution that had the participation of stakeholders and reached a solution that made sense to them.
\end{abstract}

RESUMO

INTRODUÇÃO: O Design Participativo é uma abordagem que se caracteriza pela participação ativa dos usuários como parte da equipe de design, refletindo suas perspectivas e necessidades no design do produto. O BrainDraw é uma técnica participativa para uso na fase de design da criação do produto. Este artigo investiga $o$ uso de prácticas participativas com professoras de ensino fundamental visando o redesign dos blocos de programação do TaPrEC, um ambiente de programação tangivel. OBJETIVO: Este trabalho objetivou o redesign de símbolos para os blocos de repeticão do ambiente TaPrEC, envolvendo as principais partes interessadas. MÉTODO: Um Estudo de Caso num espaco educacional que oferece atividades para as crianças durante o contraturno foi realizado utilizando a técnica BrainDraw com um grupo de professoras de ensino fundamental para o redesign dos símbolos dos blocos de repetição do ambiente TaPrEC. A experimentação e avaliação dos símbolos criados foram realizadas pelas mesmas professoras e um grupo de alunos de ensino fundamental. Também aplicamos o formulário da Autoavaliação de Emoções para avaliar a resposta afetiva dos participantes durante as atividades participativas. RESULTADOS: Os resultados das oficinas destacam que os símbolos criados pelas professoras tiveram uma melhor aceitação por parte de professoras e crianças. Esta aceitação positiva pode decorrer do fato que as soluções participativas propostas pelas professoras sugerem associações com elementos cotidianos tais como sinais de trânsito e o símbolo da multiplicação. CONCLUSÃO: O Design Participativo é um processo que envolve pesquisadores e usuários finais na criação de produtos para seu uso. Utilizando essa abordagem, estudamos diferentes propostas de símbolos para representar e entender os blocos de repetição do TaPrEC $e$ promover uma solução que contasse com a participação dos principais interessados e que fizesse sentido para eles.

\section{Introdução}

A aprendizagem é um processo contínuo que ocorre ao longo da vida toda da pessoa e permite ao sujeito compreender melhor as coisas que estão ao seu redor: a natureza, as outras pessoas e a si mesmo. A teoria de Bruner (1966) afirma que o aprendizado é um processo ativo, no qual o aprendiz constrói novas idéias ou conceitos, baseado em seus 
conhecimentos prévios e nos que estão sendo estudados. O aprendiz filtra e transforma a nova informação, infere sobre hipóteses e toma decisões, utilizando sua estrutura cognitiva. Essa estrutura cognitiva possibilita a construção de significado e organização para as novas experiências, permitindo ao aprendiz enriquecer seu conhecimento além do conceito estudado, por meio do relacionamento das novas informações com seus conhecimentos prévios. As pesquisas de Bruner sobre o desenvolvimento cognitivo revelam três etapas de processamento e representação de informações: manuseio e ação, organização perceptiva e imagens, e utilização de símbolos. Essas etapas são parte de um sistema de três camadas de representações internas: i) enativa (baseada na ação), ii) icônica (com base na imagem), e iii) simbólica (com base na linguagem). A terceira camada, a representação simbólica, constitui a forma mais elaborada de representação; a pessoa representa a informação com base em símbolos, idéias, pensamentos e conceitos. A relação entre as três camadas de representações internas (enativa, icônica e simbólica) do desenvolvimento cognitivo é essencial no processo de aprendizado. Neste artigo discutimos resultados de nossa experiência na criação de símbolos para a linguagem de programação tangível do ambiente TaPrEC (Carbajal \& Baranauskas, 2015) e como esses símbolos contribuíram para o entendimento e aprendizado desse ambiente.

Em 2015, realizamos um Estudo de Caso para avaliar o ambiente TaPrEC no qual participaram professoras e alunos de ensino fundamental. Nesse estudo verificamos que os participantes aprenderam conceitos básicos de programação (sequência, repetição, procedimento) e a lógica para construir um programa tangível. No entanto, observamos que os símbolos utilizados nos objetos tangíveis (propostos pela criadora do TaPrEC) dificultavam o entendimento dos conceitos de programação: por exemplo, os participantes confundiam o símbolo do bloco "fim da repetição" (Figura 4b) com o símbolo do bloco de controle "fim" (Figura 3a), devido ao fato que ambos os símbolos eram representados por uma forma circular. Uma das sugestões que recebemos dos professores para aprimorar nosso ambiente foi "melhorar os desenhos dos blocos de programação para facilitar a interpretação". Para os professores, os símbolos de alguns blocos de programação não comunicavam uma informação clara sobre a funcionalidade dos mesmos. Para resolver esse problema, decidimos envolver os professores no redesign dos símbolos dos blocos de programação do ambiente TaPrEC.

Vários autores (Beyer \& Holtzblatt, 1997; Nielsen \& Mack, 1994; Schuler \& Namioka, 1993) reconhecem amplamente a importância de envolver o usuário no processo de design de sistemas computacionais. A participação do usuário é sempre valiosa, pois seu papel passa de consumidor/espectador a participar como co-autor da tecnologia. Na área de Interação Humano-Computador (IHC) se praticam diferentes técnicas para envolver o usuário no processo de criação de artefatos computacionais para seu uso. O Design Participativo (DP) (Muller et al., 1997; Schuler \& Namioka, 1993) apresenta-se como um método de investigação em que o designer oferece técnicas para viabilizar a participação de usuários prospectivos na proposição de soluções que atendam às suas necessidades. Resultados de Bonacin et al. (2010) destacam que uma prática de DP deve ser encarada como um suporte ou infraestrutura para um processo complexo em grupo, e não como uma sequência rígida de passos bem compreendidos que produz um resultado garantido. No DP os usuários de tecnologia não são apenas fontes de informação ou sujeitos de observação; eles têm a capacidade de contribuir efetivamente no processo de design e desenvolvimento de sistemas computacionais.

Considerando o que foi exposto, este trabalho objetivou o redesign de símbolos para os blocos de repetição do ambiente de programação tangível para crianças, TaPrEC, envolvendo as principais partes interessadas (professores e alunos), de modo que os símbolos criados fizessem sentido para elas, e fossem adequados a suas 
necessidades e a seu contexto. Para alcançar nosso objetivo utilizamos a técnica participativa BrainDraw com um grupo de professoras de ensino fundamental durante o primeiro semestre de 2017 no contexto de um Estudo de Caso conduzido por pesquisadores da área de IHC para avaliar diferentes interfaces computacionais. O estudo foi realizado num espaço educativo que oferece atividades no contraturno da escola, na cidade de Campinas. Assim, este artigo está organizado da seguinte forma: na seção 2 realizamos a descrição do ambiente TaPrEC para programação tangível; na seção 3 apresentamos o referencial teórico-metodológico que adotamos neste trabalho; na seção 4 detalhamos as atividades realizadas com professoras e alunos de ensino fundamental durante o processo de redesign dos símbolos para o ambiente TaPrEC, e fazemos a discussão relativa aos resultados obtidos; finalmente na seção 5 apresentamos as considerações finais.

\section{TaPrEC: o Ambiente de Programação Tangível}

TaPrEC (acrônimo de Tangible Programming Environment for Children) é um ambiente de programação tangível de baixo custo desenvolvido para ensinar conceitos básicos de programação (sequências, repetições e procedimentos). $\mathrm{O}$ ambiente permite criar programas de computador na forma tangível, organizando blocos coloridos de madeira semelhantes a peças de quebra-cabeças, equipados com etiquetas de Identificação por Radiofrequência (RFID-Radio-Frecuency IDentification). A execução do programa tangível é feita no contexto de programação $S c r a t c h{ }^{l}$, um ambiente de programação criado no Massachussetts Institute of Technology (MIT). TaPrEC está constituído por um hardware de baixo custo, um software de controle e os blocos de programação com tecnologia RFID embutida (Figura 1).
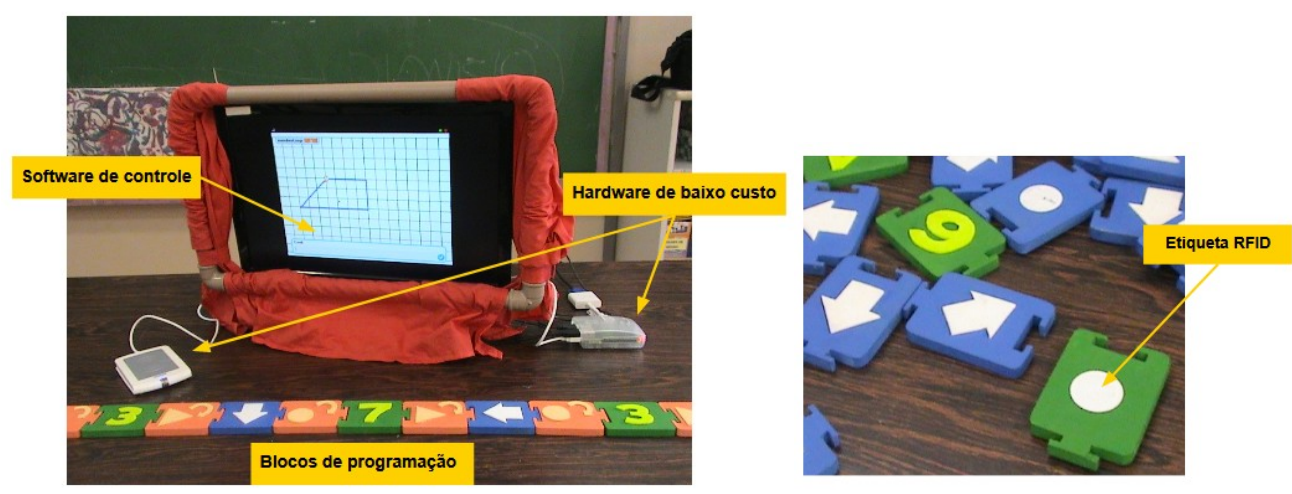

Figura 1. Componentes do ambiente TaPrEC (esquerda) e etiqueta RFID incorporada no bloco de programação (direita).

Uma das motivações principais de nosso ambiente foi utilizar tecnologia acessível a populações socioeconomicamente menos favorecidas, portanto sem fazer um enorme investimento, mantendo ao mesmo tempo a qualidade da interação e o potencial do ambiente de aprendizado de conceitos de programação. Com esse propósito, escolhemos como hardware principal o Raspberry $\mathrm{Pi}^{2}$, um computador de placa única do tamanho de um cartão de crédito, que possui todas as funcionalidades básicas de qualquer computador desktop, como navegar na Internet, reproduzir vídeos de alta definição, fazer planilhas, processamento de texto e jogos. Utiliza um cartão de memória SecureDigital (SD) para armazenamento permanente, precisa de uma fonte de alimentação externa, pode ser conectado a um aparelho de televisão ou a um monitor de

${ }^{1}$ https://www.scratch.mit.edu/

${ }^{2} \mathrm{https}$ ://www.raspberrypi.org/ 
computador, aceita conexão de mouse e teclado por meio de entradas Universal Serial Bus (USB) e possui uma entrada Ethernet. A outra tecnologia utilizada no ambiente TaPrEC é a Identificação por Radiofrequência (RFID), que é uma tecnologia de identificação automática que pode ser utilizada para fornecer um identificador único a objetos físicos. Um típico sistema RFID é composto principalmente por um leitor, etiquetas e um sistema de processamento de dados. A comunicação ocorre através de sinais de radio, onde a informação é enviada por meio da antena de uma etiqueta para um leitor ou vice-versa.

Desenvolvido na linguagem de programação Scratch, o software de controle se encarrega de armazenar os identificadores das etiquetas RFID embutidas nos blocos de programação e associar cada identificador com um c. Como ilustramos na Figura 2, é por meio do leitor RFID que os identificadores são enviados ao software de controle; o programa principal verifica se o identificador está armazenado em lista de identificadores e depois é inserido temporariamente na fila de processamento; quando o programa principal recebe o identificador do bloco "fim", o código Scratch associado a cada identificador da fila de processamento é executado, e o resultado da execução é mostrado no ambiente Scratch. A escolha de Scratch para desenvolver o software de controle responde à necessidade de criar um software que facilite ao professor a customização do ambiente TaPrEC, de forma independente de um desenvolvedor do sistema.

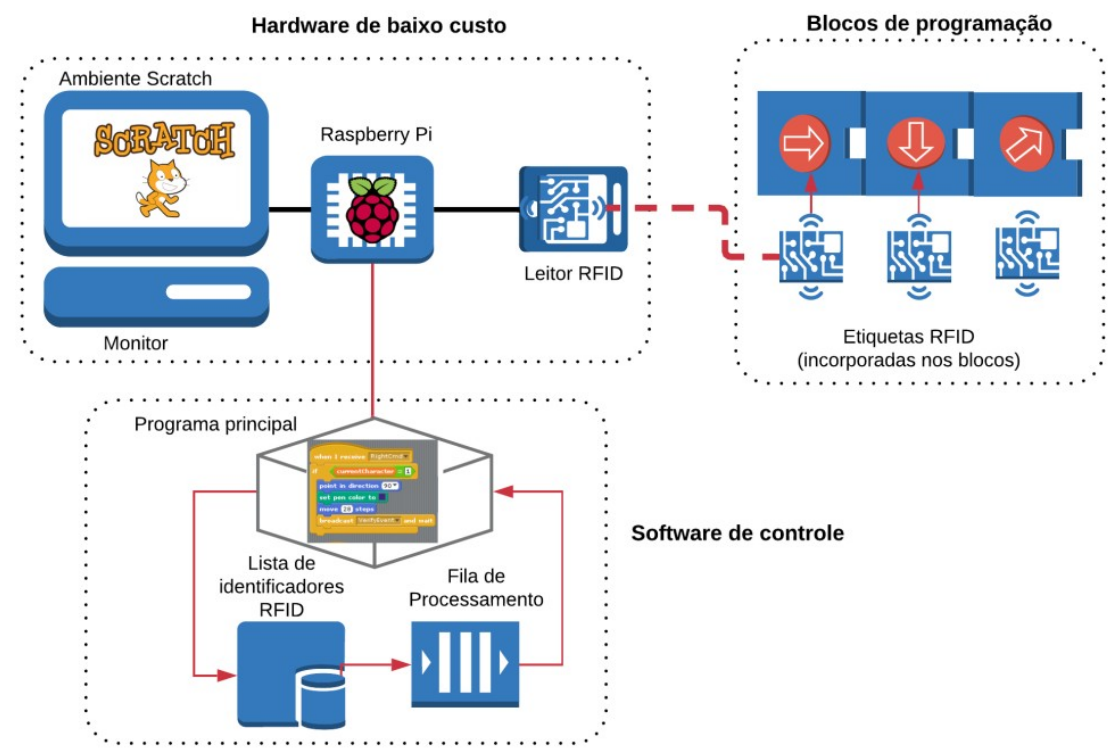

Figura 2. Arquitetura do ambiente TaPrEC.

Os blocos de programação são blocos coloridos de madeira semelhantes a peças de quebra-cabeças que contém em um dos lados uma etiqueta RFID e no outro lado um símbolo em alto-relevo para representar sua funcionalidade (Figura 1). O ambiente TaPrEC possui diferentes tipos de blocos de programação agrupados de acordo a sua funcionalidade e com uma cor característica: cinza para os blocos de controle (Figura 3a), azul para os blocos de deslocamento (Figura 3b), laranja para os blocos de repetição (Figura 3c), verde para os blocos de números (Figura 3d) e amarelo para os blocos de procedimentos (Figura 3e). 


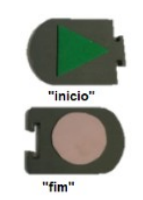

a.

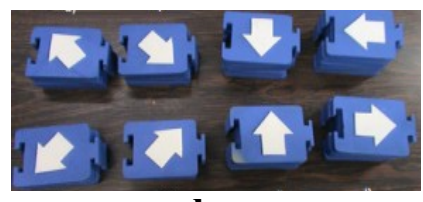

b.

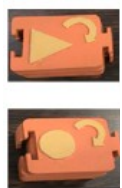

c.

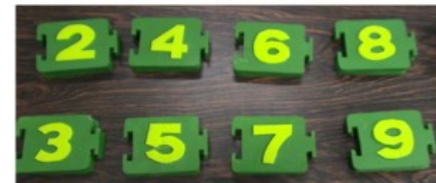

d.

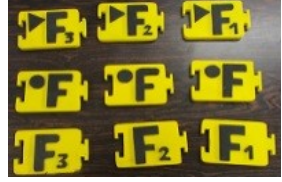

e.

Figura 3. Tipos de blocos de programação do ambiente TaPrEC: a) controle, b) deslocamento, c) repetição, d) números, e) procedimentos.

Na Figura 4 mostramos em detalhe os blocos de repetição: i) o bloco "inicio da repetição" (Figura 4a) é colocado à frente dos blocos que serão repetidos; ii) o bloco "fim da repetição" (Figura 4b) marca o fim da sequência de blocos que serão repetidos. Para montar um programa tangível que utilize uma repetição, primeiro colocamos um bloco de número (Figura 3d) para indicar o número de repetições, depois colocamos o bloco "inicio da repetição" seguido dos blocos que serão repetidos (por exemplo, blocos de deslocamento) e finalmente o bloco "fim da repetição". Na Figura 4c (à esquerda) ilustramos um exemplo de um programa tangível que utiliza uma estrutura repetitiva indicando que o personagem repetirá três vezes as seguintes ações: dois movimentos "para frente" e um movimento "para cima". Para que o programa tangível seja enviado ao software de controle é preciso passar o leitor RFID por cada bloco de programação, o software recebe os identificadores das etiquetas RFID, processa-os e mostra o resultado no ambiente de programação Scratch (Figura 4c à direita).

a.

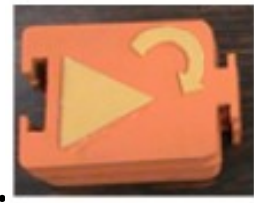

b.

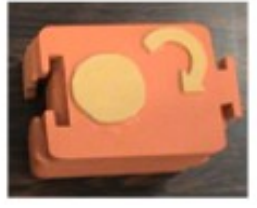

c.

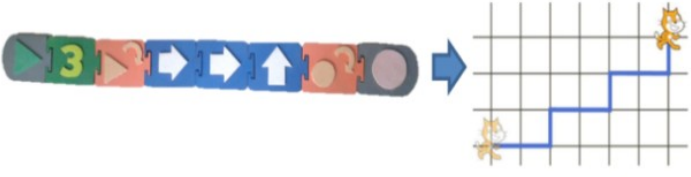

Figura 4. Blocos de repetição e seu funcionamento: a) bloco "inicio da repetição", b) bloco "fim da repetição", c) programa tangível com uma estrutura repetitiva.

\section{Referencial Teórico-Metodológico}

Nas subseções seguintes apresentamos a abordagem do Design Participativo e a técnica BrainDraw que utilizamos para envolver as professoras no redesign de símbolos para os blocos de repetição do ambiente TaPrEC. Também apresentamos o formulário da Autoavaliação de Emoções (Bradley \& Land, 1994), um instrumento utilizado para avaliar a resposta afetiva dos participantes durante a realização das atividades.

\subsection{Design Participativo}

A abordagem de Design Participativo (DP) surgiu na Escandinávia na década de 70, como uma proposta para que trabalhadores pudessem participar das decisões relativas ao uso de novas tecnologias no seu ambiente de trabalho. O DP propõe a participação do usuário final, de forma ativa, nas várias etapas de desenvolvimento de tecnologias (Muller et al., 1997). Segundo Bonacin (2004), o DP possibilita aos envolvidos uma visão diferenciada em que se tem a exploração de novas estruturas, protótipos de novos sistemas e requisitos de sistemas. Três características específicas definem o DP: i) ele é orientado ao contexto (de trabalho); ii) envolve a colaboração em vários níveis e, iii) apresenta uma abordagem iterativa ao design. Entre seus benefícios estão as decisões democráticas, o compartilhamento de experiências e de conhecimentos entre as diferentes partes interessadas, assim como a aceitação do produto construído de forma colaborativa (Mombach et al., 2010).

O DP é conduzido com métodos e práticas a serem realizadas com o usuário, que se caracterizam pelo pouco comprometimento com recursos e por serem de simples 
execução. Muller et al. (1997) destacam 61 métodos e práticas para serem aplicadas a diferentes fases de desenvolvimento de um produto de software. A técnica participativa BrainDraw, utilizada na fase de design, caracteriza-se por um brainstorming cíclico e gráfico no qual cada participante faz um desenho inicial em uma folha de papel e transcorrido um intervalo de tempo (curto) passa seu desenho para o colega, que continua o desenho encontrado na folha. O processo continua rodando até que todos tenham colaborado na criação de cada um dos outros participantes. Como resultado geram-se varias propostas à interface do sistema que podem ser consolidadas pelo grupo em uma única versão.

\subsection{Autoavaliação de Emoções}

A autoavaliação de estados afetivos (SAM - Self-Assessment Manikin) (Bradley \& Lang, 1994) consiste em um sistema de classificação pictórica para avaliar a satisfação, motivação e controle em resposta a um objeto ou evento. Com base no modelo PAD (Pleasure, Arousal, Dominance), as escalas da Autoavaliação de Emoções apresentam vários bonecos (manikins) ao longo das três dimensões afetivas (Figura 5). Na dimensão de satisfação (primeira linha), a escala varia de um boneco de expressão feliz e sorridente a um boneco de expressão triste. Na dimensão de motivação (segunda linha), as expressões variam de uma figura animada com os olhos abertos até uma figura sonolenta. A dimensão de controle (terceira linha) representa o domínio sobre o objeto ou situação e está relacionada às mudanças no tamanho das figuras: a figura maior indica o máximo controle da situação. Nesta dimensão a escala está propositalmente apresentada na ordem inversa das dimensões anteriores, isto é, do menor controle da situação ao maior controle, como medida de captura de possível viés na obtenção de respostas.
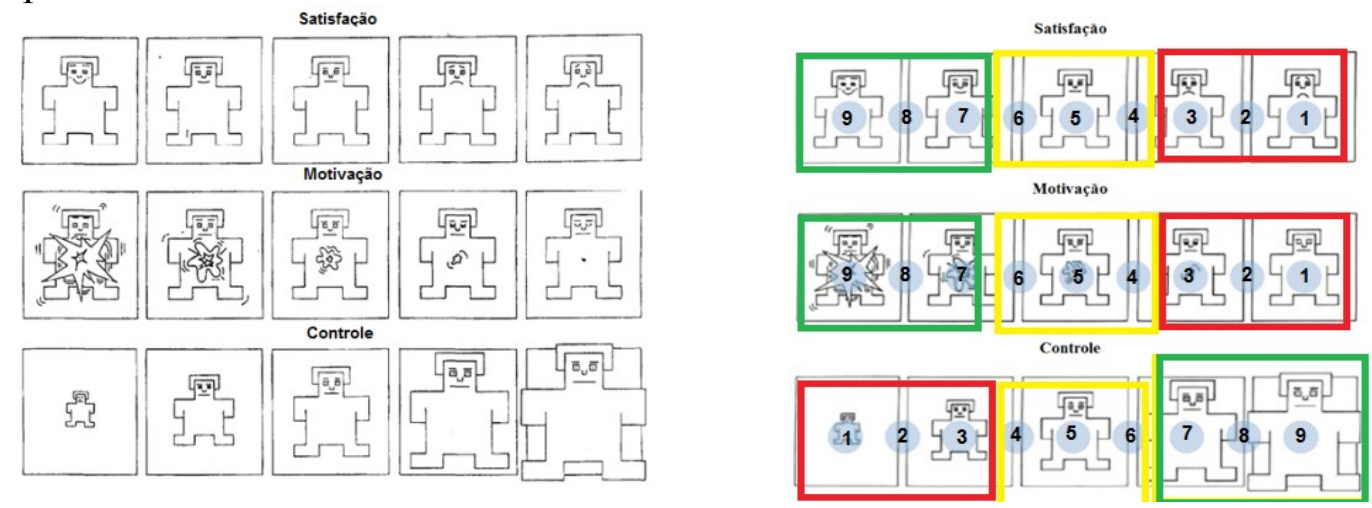

Figura 5. Formulário da Autoavaliação de Emoções (esquerda) e nosso método de análise (direita).

Neste trabalho colocamos para cada dimensão afetiva uma escala de 9 pontos representados por círculos e analisamos os resultados da seguinte maneira: os valores mais altos (7, 8 e 9) representam uma resposta afetiva positiva, sendo o valor 9 a intensidade mais alta; os valores intermediários $(4,5$ e 6$)$ representam uma resposta afetiva neutra; e os valores mais baixos (1, 2 e 3 ) representam uma resposta afetiva negativa.

\section{Um Estudo sobre o Redesign de Símbolos para o ambiente TaPrEC}

Para envolver as professoras no redesign dos símbolos dos blocos de repetições utilizamos a técnica participativa BrainDraw. Este contexto de participação mais ativa das professoras possibilitou que elas se expressassem sobre o que pensam, sentem, questionam e sugerem sobre a tecnologia computacional com a qual se deparam, bem 
como as atividades que gostariam de realizar utilizando o ambiente TaPrEC. As atividades apresentadas nas subseções seguintes dizem respeito a atuação de professoras de ensino fundamental no redesign dos símbolos para os blocos de c do ambiente TaPrEC; e a experimentação e avaliação dos símbolos redesenhados com alunos e professoras de ensino fundamental, no contexto de um espaço educacional real.

\subsection{Cenário e Participantes}

As atividades relacionadas ao redesign de símbolos para os blocos de repetição tiveram lugar no Programa de Integração e Desenvolvimento da Criança e do Adolescente (PRODECAD), que oferece educação suplementar a crianças de 6 a 14 anos, matriculadas na EEPG "Sérgio Pereira Porto". As atividades do PRODECAD ocorrem dentro do campus da Universidade Estadual de Campinas (UNICAMP), São Paulo, em horário de contraturno ao ensino regular. As atividades deste estudo foram agendadas formalmente pela coordenação dessa unidade educacional, como parte das "Oficinas de Interfaces Computacionais" que têm sido conduzidas semestralmente por pesquisadores da área de IHC desde o ano 2014. Sete professoras (entre 33 e 52 anos) de ensino fundamental participaram da realização do BrainDraw. A avaliação dos símbolos foi realizada pelas mesmas professoras e um total de doze alunos (de 7 a 10 anos). $O$ grupo de crianças era diverso em termos de diferentes anos escolares e já estavam alfabetizadas. Professoras e alunos eram da turma da manhã do PRODECAD.

\subsection{As Oficinas e seus Resultados}

Durante o primeiro semestre de 2017, no mês de abril, agendamos três oficinas com uma duração de 60 minutos cada para realizar as atividades. $\mathrm{Na}$ primeira oficina realizamos o BrainDraw com as professoras; na segunda oficina, as professoras criaram programas tangíveis com estruturas repetitivas para avaliar dois tipos de blocos de repetição: i) blocos com símbolos propostos pelas professoras e ii) blocos com símbolos propostos pela criadora do TaPrEC; na terceira oficina os alunos criaram programas tangíveis com estruturas repetitivas para avaliar os dois tipos de blocos de repetição. Ao finalizar cada oficina os participantes preenchiam o formulário da autoavaliação de estados afetivos. A seguir apresentamos em detalhe as atividades desenvolvidas em cada oficina e seus principais resultados.

\section{Oficina 1: BrainDraw}

Trabalhamos com sete professoras que já tinham participado das "Oficinas de Interfaces Computacionais" no primeiro semestre de 2015. Naquele semestre as professoras tiveram contato com a primeira versão de TaPrEC (Carbajal \& Baranauskas, 2015) e colaboraram efetivamente com sugestões que foram considerados na segunda versão do ambiente (Carbajal \& Baranauskas, 2016). Na Figura 6 mostramos os blocos de repetição da primeira versão de TaPrEC que não tinham símbolos gráficos e eram representadas pelas palavras "INICIO REPETIR" e "FIM REPETIR".

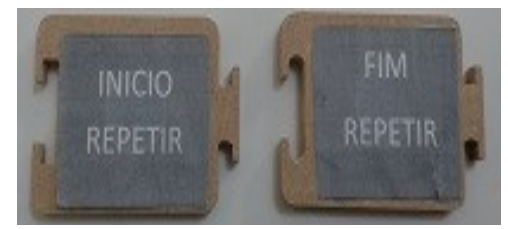

Figura 6. Blocos de repetição da primeira versão de TaPrEC. 
Buscando identificar quanto as professoras lembravam-se do funcionamento do ambiente de programação tangível, a pesquisadora colocou na mesa de trabalho os blocos da primeira versão de TaPrEC e perguntou: "Alguém pode explicar como funcionam os blocos de repetição?". Uma professora respondeu: "Por exemplo, se você quer ir reto cinco vezes, primeiro coloca o inicio..." (pegando o bloco INICIO REPETIR) "depois deve colocar o bloco da ação" (pegando um bloco de deslocamento) e "depois colocar este bloco" (pegando o bloco FIM REPETIR). Quase todas as professoras concordaram com a descrição da sua colega. Observamos que as professoras lembravam parcialmente como utilizar os blocos de repetição já que não utilizaram o bloco de número para indicar o número de repetições. Imediatamente a pesquisadora explicou o funcionamento dos blocos de repetição e uma vez solucionadas as dúvidas das professoras, explicou o objetivo da oficina: criar símbolos para representar graficamente a funcionalidade dos blocos "inicio da repetição" e "fim da repetição" de forma que fossem fáceis de serem identificados por qualquer aluno ou professora. A pesquisadora explicou também a técnica participativa BrainDraw.

Após essa primeira etapa, as professoras formaram duas equipes. Em cada equipe participou um pesquisador da área de IHC. Iniciamos o BrainDraw realizando rodadas de 1 minuto (Figura 7). Observamos que a primeira rodada resultou difícil para algumas professoras porque não conseguiram desenhar nada. A partir da segunda rodada as idéias e desenhos fluíram naturalmente como ilustramos nas Figuras 8a e 9a. Uma vez finalizadas as rodadas, cada equipe realizou a discussão e consolidação dos símbolos criados de modo que resultasse um único símbolo para o bloco "inicio da repetição" e outro para o bloco "fim da repetição". Durante a etapa de consolidação, uma das professoras da equipe 1 explicava para outra o que significava seu desenho: "o verde é para começar". Na equipe 2 , uma professora explicava para as colegas: " $R$ é repetição, e F é fim da repetição". Uma vez que consolidaram suas idéias, uma representante de cada equipe explicou para todos os participantes da oficina como chegaram aos símbolos finais (Figuras $8 \mathrm{~b}$ e 9b) e o significado dos mesmos.
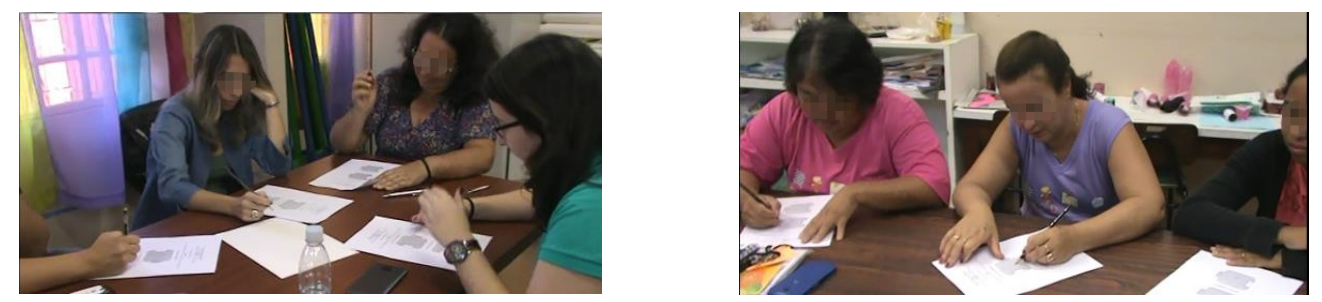

Figura 7. Professoras participando das rodadas do BrainDraw.

O relato oral transcrito a seguir revela como as professoras de cada equipe representaram o funcionamento dos blocos de repetição.

Professora equipe 1: "Inicio repetir é o simbolo de vezes $X$, porque a criança sabe que vezes representa repetir. Para parar a repetição utilizamos a mãozinha em sinal de pare. Usamos a cor vermelho porque no sinal de trânsito vermelho indica pare e a cor verde indica vai". 


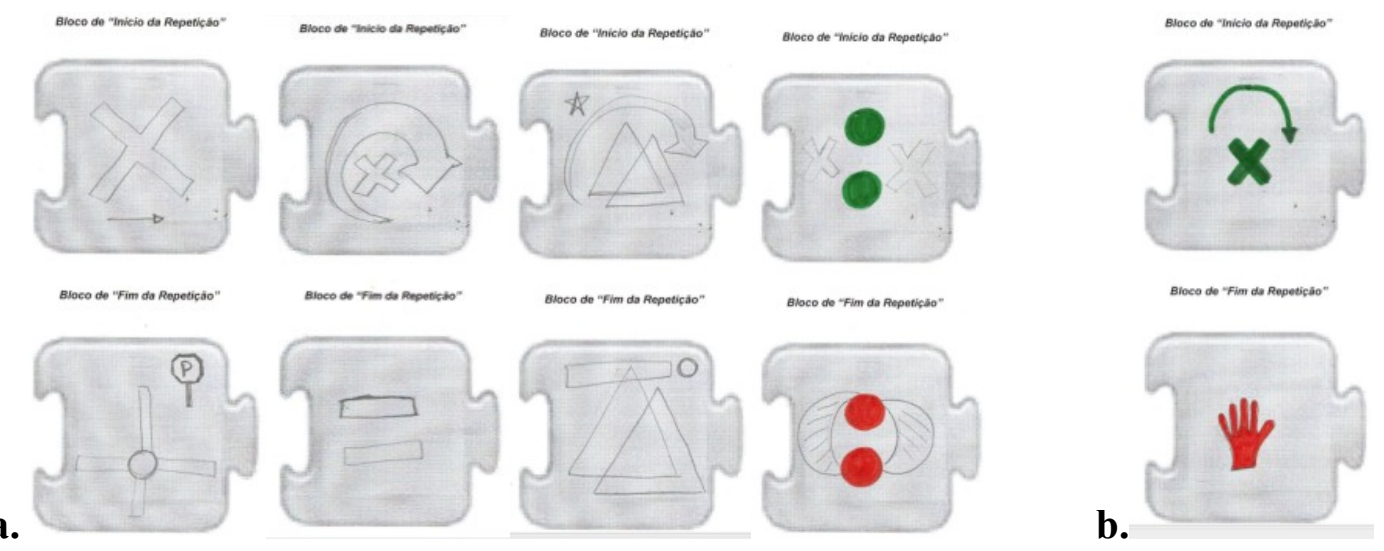

Figura 8. Resultados BrainDraw da equipe 1: a) símbolos criados nas rodadas, b) símbolos finais.

Professora equipe 2: "A gente utilizou o verde para continuar e o vermelho para parar. A gente pensou na multiplicação e indica as vezes que qualquer numero vai repetir. $O$ triângulo simboliza a continuidade. Para finalizar a repetição utilizamos o ponto, que é um ponto final daquele momento".

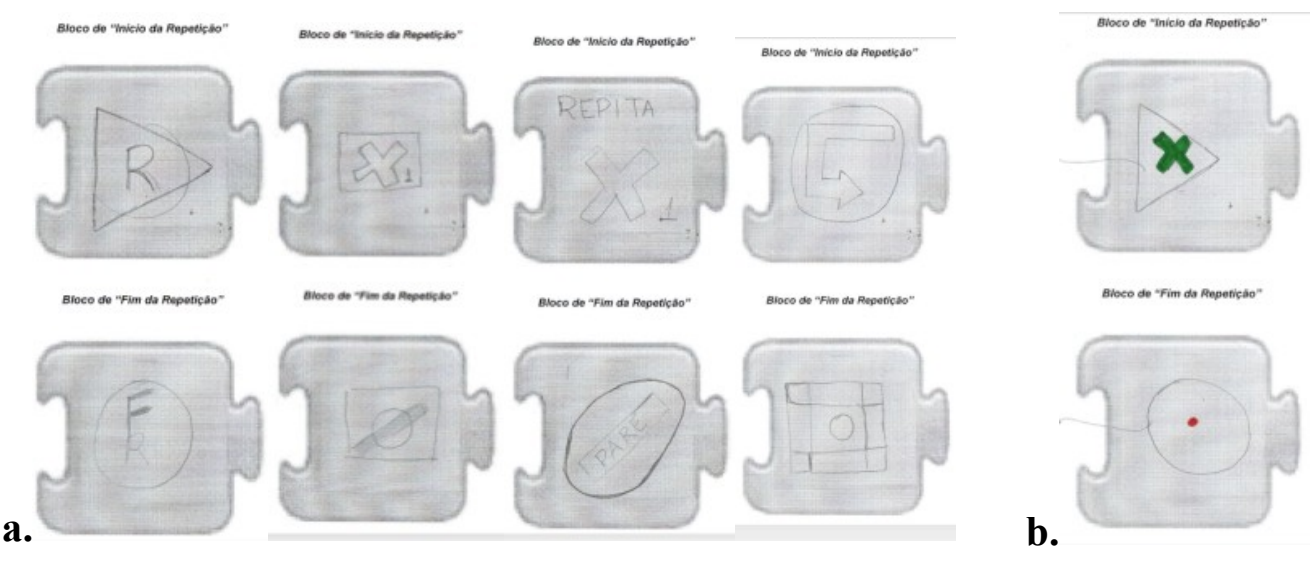

Figura 9. Resultados BrainDraw da equipe 2: a) símbolos criados nas rodadas, b) símbolos finais.

Para finalizar a oficina, as participantes preencheram o formulário da Autoavaliação de Emoções para que avaliassem sua resposta afetiva com relação à técnica BrainDraw. Na Figura 10 apresentamos os resultados obtidos.

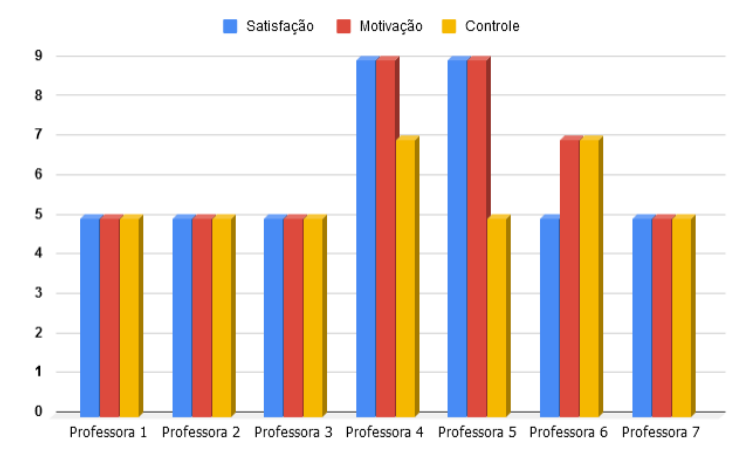

Figura10. Resultados da Autoavaliação de Emoções da Oficina 1.

Observamos que todos os resultados estão entre os pontos 5 e 9 da escala, o que significa que os resultados variam entre neutro e positivo. As maior parte das respostas 
se concentram no ponto 5 , então podemos afirmar que a maior parte das professoras teve uma resposta afetiva neutra para as três dimensões afetivas.

\section{Oficina 2: Experimentação e avaliação das professoras}

Utilizando os símbolos criados pela equipe 1 durante o BrainDraw (Figura 8b) construímos novos blocos de repetição (Figura 11). Para a segunda oficina disponibilizamos os dois tipos de blocos de repetição: i) a proposta das professoras da equipe 1; e ii) a proposta da criadora de TaPrEC (Figuras 4a e 4b). O objetivo da oficina foi que as professoras criassem programas tangíveis com estruturas repetitivas e opinassem sobre quais blocos resultavam mais fáceis de entender e representavam melhor a idéia de repetição.

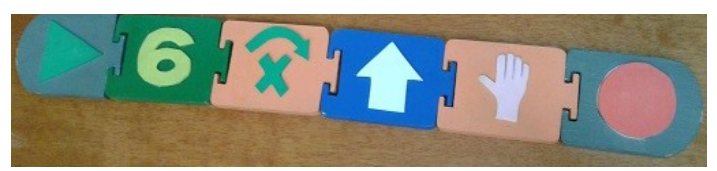

Figura 11. Proposta das professoras da equipe 1 para os blocos de repetição.

Propusemos um exercício que consistia em movimentar um personagem desde uma posição inicial até a posição de outro personagem. Enquanto o personagem se movimentava seu caminho era marcado (Figura 12).

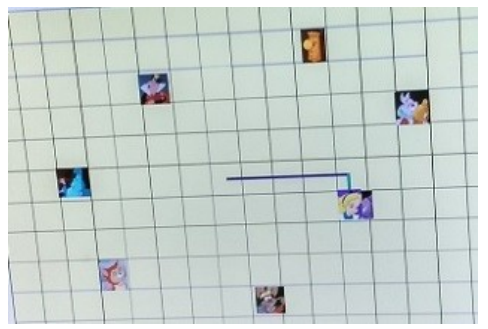

Figura 12. Exercício proposto na Oficina 2 com as professoras.

As professoras trabalharam em duas equipes e planejaram em papel o programa tangível (Figura 13a). Cada equipe utilizou apenas um tipo de bloco de repetição para criar a solução ao exercício proposto. A equipe 1 utilizou os novos blocos de repetição e a equipe 2 utilizou a proposta da pesquisadora. Depois as professoras montaram seus programas tangíveis, passaram o leitor de RFID sobre os blocos de programação (Figura 13b) e observaram o resultado no monitor (Figura 13c).
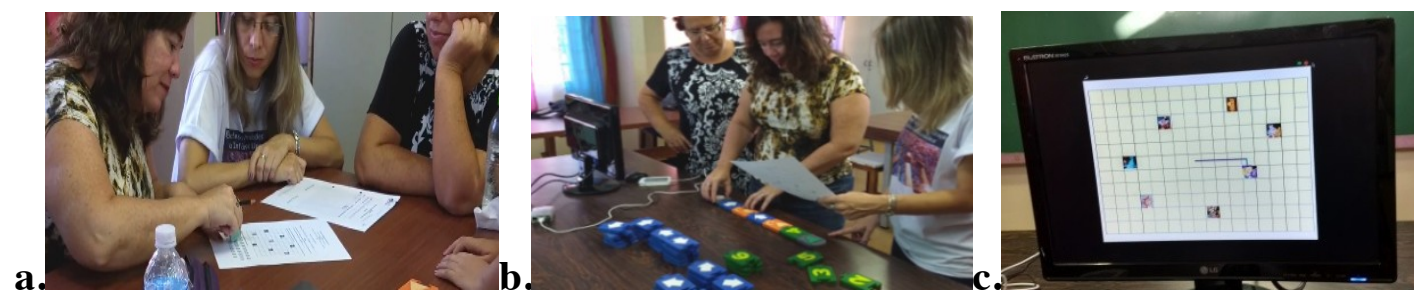

Figura 13. Oficina 2: a) planejamento da solução ao exercício, b) montagem do programa tangível, c) resultado da execução do programa tangível.

Observamos que a equipe 2 tinha algumas dificuldades para identificar a funcionalidade dos blocos de programação e corrigiu duas vezes seu programa tangível. Para realizar as correções reorganizaram diretamente os blocos de programação. Segundo o observado, as professoras da equipe 2 tinham dificuldade para lembrar a sintaxe de uma estrutura repetitiva no ambiente TaPrEC. Apesar disso, ambas as equipes conseguiram completar o exercício corretamente. Após a etapa de experimentação, juntamos as duas equipes para realizar uma discussão geral da oficina. Nesse momento as professoras de ambas as 
equipes explicaram como criaram seus programas tangíveis e como resolveram o exercício. Depois todas as professoras foram consultadas sobre qual proposta segundo sua opinião representava melhor o conceito de repetição e era mais fácil de entender. Uma professora da equipe 2 comentou que achava que o ambiente tinha "muitos símbolos para a criança decorar". Outra professora da equipe 2 falou que a proposta da pesquisadora tinha "muita semelhança" com os blocos de controle, sugerindo que isso causa confusão entre esses dois tipos de blocos. Uma professora da equipe 1 afirmou que para ela as duas propostas "podiam dar certo, mas pensando nas crianças a proposta da mãozinha era mais atraente e fácil de entender". No entanto, outra professora da equipe 2 tinha problemas com essa proposta já que "a meia flecha acima do X" passava para ela a idéia de "meio caminho" ou alguma ação incompleta, e não a idéia de repetição. Essa mesma professora sugeriu utilizar os "parênteses da multiplicação" como símbolos dos blocos de repetição. As professoras concordaram que os parênteses seriam uma ótima representação para os blocos de repetição porque as crianças já estavam familiarizadas com esses símbolos. Uma vez que as professoras expressaram suas opiniões, preencheram o formulário da Autoavaliação de Emoções.

Os resultados (Figura 14) mostram que, com relação às dimensões afetivas de satisfação e motivação a maioria das professoras teve uma resposta afetiva positiva. Com relação à dimensão de controle (domínio sobre a atividade), as respostas se concentram no ponto 5 , então a maioria das professoras teve uma resposta afetiva neutra para esta dimensão afetiva.

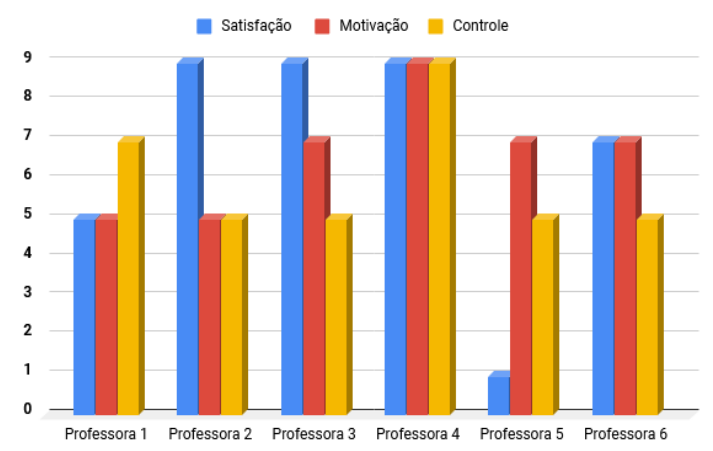

Figura 14. Resultados da Autoavaliação de Emoções das professoras na Oficina 2.

\section{Oficina 3: Experimentação e avaliação dos alunos}

Doze alunos participaram da terceira oficina. Os alunos já tinham experimentado o ambiente TaPrEC num outro encontro, então estavam familiarizadas com a programação tangível. Inspirados numa cena da história da "Alice nos Pais das Maravilhas" onde o personagem do Coelho repetia a frase "é tarde, é tarde", o exercício proposto para esta oficina foi criar um programa tangível para que o personagem repetisse varias vezes essa frase. A fala foi armazenada no software de controle como um arquivo mp4. Associamos o arquivo mp4 com um bloco de programação de modo que quando os alunos passassem o leitor RFID por esse bloco a fala era ouvida e um quadro de texto com a frase "é tarde" aparecia no ambiente Scratch. Os alunos formaram duas equipes: a equipe 1 utilizou a proposta da pesquisadora para os blocos de repetição, e a equipe 2 utilizou a proposta das professoras. Para planejar o programa tangível cada equipe recebeu a descrição da atividade em papel (Figura 16a). Uma vez planejada a solução (Figura 15a), os alunos começaram a montar seus programas tangíveis organizando os blocos de programação na mesa de trabalho. Finalmente cada equipe passou o leitor RFID pelos blocos de programação (Figura 15b) e todos observaram o resultado no ambiente Scratch (Figura 15c). 

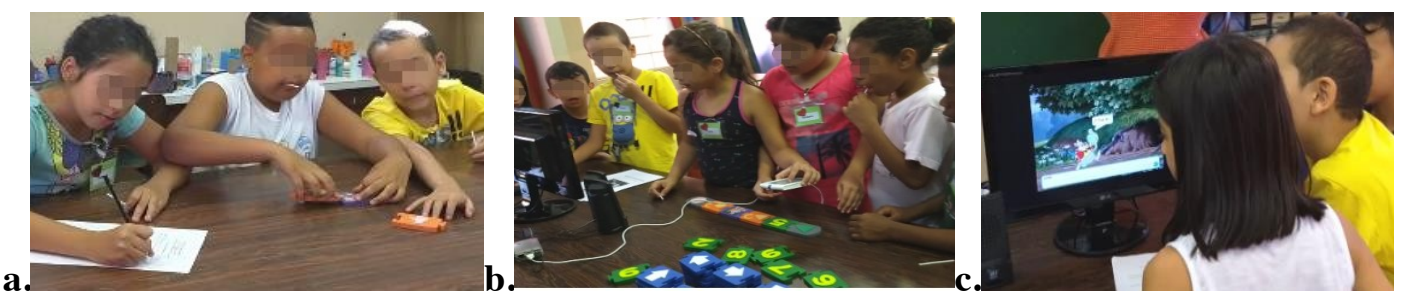

Figura 15. Oficina 3: a) alunos planejando o programa tangível, b) alunos montando o programa e c) resultado mostrado no ambiente Scratch.

Na primeira tentativa, a equipe 1 utilizou dois blocos de número no seu programa tangível. Questionados sobre essa ação, um dos alunos expressou que queria utilizar um número de dois dígitos no programa tangível. A pesquisadora explicou que o TaPrEC aceita apenas um bloco de número na estrutura repetitiva. Após a explicação, conseguiram montar o programa tangível corretamente. A equipe 2 precisou de ajuda da pesquisadora para lembrar como montar uma estrutura repetitiva (sintaxe) e depois conseguiram montar seu programa tangível corretamente. Para verificar se os alunos entenderam realmente o funcionamento dos blocos de repetição, realizamos uma avaliação individual que consistia numa folha de papel onde cada criança devia explicar o significado de cada bloco do programa tangível criado pelo seu grupo. Na Figura 16b mostramos dois exemplos de respostas dos alunos ao exercício de avaliação.

a.

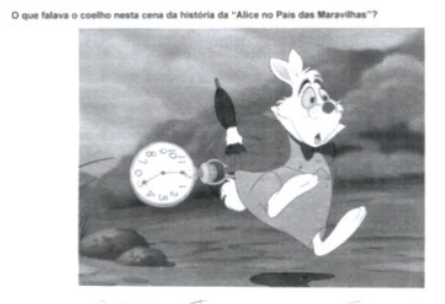

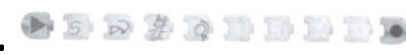

b.

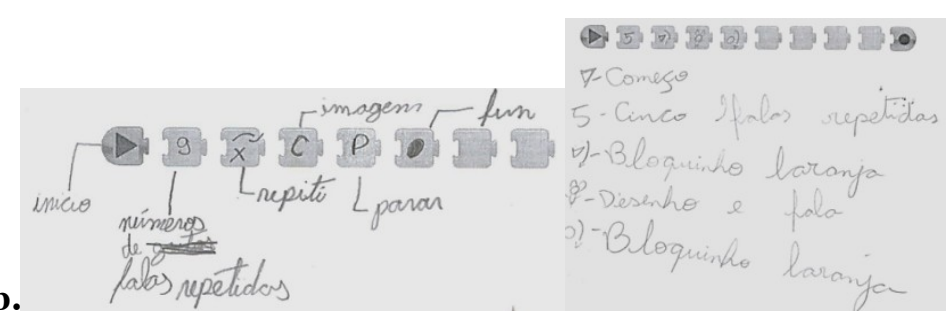

Figura 16. Oficina 3: a) exercício proposto, b) respostas das crianças ao exercício de avaliação individual.

Ao revisar as respostas individuais das doze crianças encontramos que: i) dos seis alunos que utilizaram a proposta das professoras, quatro conseguiram descrever corretamente a função de cada bloco do seu programa tangível; e dois responderam parcialmente correto, isto é, descreveram corretamente alguns blocos de programação; ii) dos seis alunos que utilizaram a proposta da pesquisadora, dois alunos responderam parcialmente correto; e quatro não conseguiram descrever os blocos de programação, mas indicaram o resultado da execução do programa, por exemplo escreveram "para mover o coelho". Como observamos, os alunos que responderam corretamente a avaliação individual eram parte da equipe que utilizou os símbolos criados pelas professoras; vários alunos que utilizaram a proposta da pesquisadora erraram no momento de explicar a funcionalidade dos blocos de programação. Para finalizar a oficina as crianças preencheram o formulário de Autoavaliação de Emoções cujos resultados são mostrados na Figura 17. 


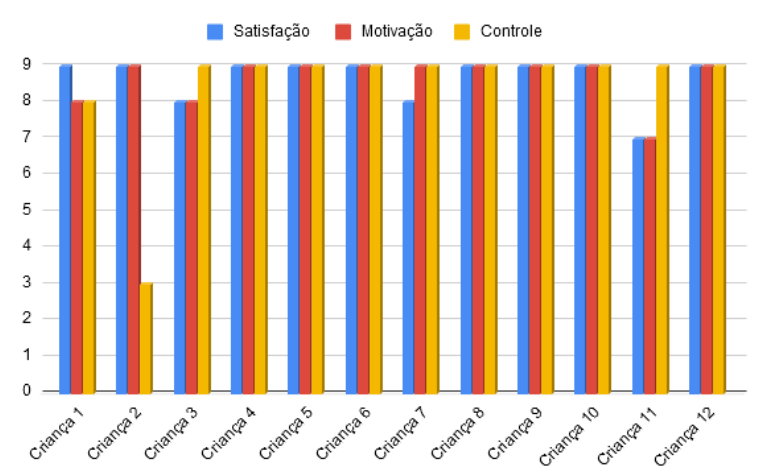

Figura 17. Resultados da Autoavaliação de Emoções dos alunos na Oficina 3.

Observamos nos resultados da Autoavaliação de Emoções que a maior parte dos alunos avaliaram com 9 as três dimensões afetivas, isto significa que tiveram uma resposta afetiva bastante positiva para a satisfação, motivação e controle, para a oficina, independentemente da equipe.

\subsection{Discussão}

Os resultados das oficinas, conforme apresentados na seção anterior, destacam que os símbolos criados pelas professoras tiveram uma melhor aceitação por parte de professoras e alunos, refletida também no uso que as crianças fizeram em seu programa tangível. Esta aceitação pode decorrer do fato que as soluções participativas propostas pelas professoras sugerem associações com elementos cotidianos, tais como os sinais de trânsito e o símbolo da multiplicação para representar o número de repetições com o 'vezes' (x) de 'repetir um número de vezes'. A proposta das professoras de redesign dos blocos de repetição fez uso do caráter icônico (e metafórico) da representação enquanto que na versão apresentada pela pesquisadora, os elementos gráficos eram signos da categoria simbólica (abstratos), assim como a representação original em texto. Do ponto de vista semiótico, esse resultado mostra a facilitação de interpretação de ícones em comparação a símbolos (gráficos ou textuais) que, baseados em convenções, demandam processo de decodificação. Nesse sentido, as práticas participativas com as partes interessadas mostraram sua efetividade em trazer tais elementos icônicos para a representação nos blocos.

As equipes de trabalho conseguiram planejar e executar corretamente suas soluções tangíveis para as atividades propostas. No entanto, os seis alunos que trabalharam com os blocos de repetição propostos pela pesquisadora não conseguiram ou tiveram dificuldades em explicar corretamente seu programa tangível, sugerindo, assim, que a representação simbólica (os símbolos abstratos na proposta da pesquisadora) desses blocos não facilitava sua interpretação da linguagem dos blocos do programa tangível, para representar o conceito de repetição. É possível que esses alunos tenham se valido também das cores e formas dos blocos para experimentar e montar a solução correta. Interessante notar que essa diferença na semântica dos elementos parece ter afetado também a compreensão da sintaxe do programa, observada na dificuldade em posicionar corretamente os blocos na estrutura do programa.

A resposta afetiva (neutra) das professoras para a atividade do BrainDraw pode ter sido originada pelo tempo curto $(1$ minuto) das rodadas especificado para essa técnica, o que pode ter ocasionado certa frustração nas participantes, que não conseguiram desenhar nada durante as primeiras rodadas. Apesar disso, na segunda 
oficina, percebemos que as professoras ficaram felizes ao ver os blocos de repetição com os símbolos que elas mesmas criaram e seu uso pelas crianças. Isto se refletiu na resposta afetiva para essa segunda oficina, que foi majoritariamente positiva para as dimensões de satisfação e motivação. Ainda assim, observa-se a neutralidade na dimensão controle, sugerindo barreiras no aspecto do domínio da tecnologia, que precisariam ser melhor investigadas.

Em síntese, a proposta de redesign realizada pelas professoras nos blocos de repetição levou a representação da linguagem dos blocos, do simbólico representado pela solução inicial da pesquisadora, para o icônico, que parece ter feito mais sentido como o resultado de uso pelos alunos sugere. Novos estudos podem ainda ser conduzidos para explorar o aspecto enativo da interação delas com a programação tangível.

\section{Considerações Finais}

É por meio da análise de como as pessoas se apropriam e utilizam novas tecnologias e recursos computacionais que são possíveis modificações e melhoras nos produtos da tecnologia; assim conceitos de áreas como a computação e, mais especificamente pesquisa em pensamento computacional, podem ser incorporados mais naturalmente em ambientes educacionais, em favor da aprendizagem prazerosa dos alunos. O Design Participativo é um processo que envolve pesquisadores e usuários finais na criação de produtos para seu uso; como tal, apresenta potencial para a criação de produtos que fazem sentido aos usuários. Este trabalho teve como objetivo estudar diferentes propostas de signos para a representação e entendimento dos blocos de repetição do ambiente TaPrEC, visando promover uma solução que tivesse a participação dos interessados, e que fizesse sentido para eles. Utilizamos a técnica participativa BrainDraw como ferramenta para a obtenção de alternativas de design de acordo com o ponto de vista de professoras de ensino fundamental que participam de um projeto conjunto. Foi possível testar e avaliar uma das soluções criadas pelas professoras obtendo resultados positivos na aceitação e entendimento por parte de crianças e professoras, quando comparada à solução proposta pela pesquisadora. Acreditamos ter dado um passo adiante para melhorar nosso ambiente de programação tangível utilizando soluções criadas pelos próprios usuários (professoras) e experimentadas por ambos, professoras e alunos. Além disso, o trabalho mostrou a efetividade de técnicas participativas e também desafios que devem ser investigados na adaptação de tais técnicas para um contexto educacional específico. Ao mesmo tempo, indicamos novas oportunidades de pesquisa, que investiguem aspectos enativos para a programação tangível.

\section{Agradecimentos}

O presente trabalho foi realizado com apoio da Coordenação de Aperfeiçoamento de Pessoal de Nível Superior - Brasil (CAPES) - Código de Financiamento 001 (\#1545149/2015 e \#1654045/2016), do Conselho Nacional de Desenvolvimento Científico e Tecnológico - Brasil (CNPq) (\#140536/2019-1 e \#306272/2017-2), e da Fundação de Amparo à Pesquisa do Estado de São Paulo (FAPESP) (\#2015/16528-0). Também agradecemos a disponibilidade e participação dos alunos e professoras do Programa de Integração e Desenvolvimento da Criança e do Adolescente (PRODECAD) da Universidade Estadual de Campinas (UNICAMP). 


\section{Referências}

BEYER, H.; HOLTZBLATT, K. Contextual design: defining customer-centered systems. Morgan Kaufmann Publishers Inc, San Francisco, 1997.

BONACIN, R. Um modelo de desenvolvimento de sistemas para suporte a cooperação fundamentado em design participativo e semiótica organizacional (Tese de Doutorado). Disponível em: Repositório da Produção Cientifica e Intelectual da UNICAMP: http://repositorio.unicamp.br/jspui/handle/REPOSIP/276415. Doutorado em Ciência da Computação-Instituto de Computação, Universidade Estadual de Campinas, Campinas, 2004.

BONACIN, R.; MELO, A. M.; SIMONI, C. A.; BARANAUSKAS, M. C. C. Accessibility and Interoperability in e-government systems: outlining an inclusive development process. Universal Access in the Information Society, vol. 9, no 1, p. 17$33,2010$.

BRADLEY, M. M.; LANG, P. J. Measuring emotion: the self-assessment manikin and the semantic differential. Journal of behavior therapy and experimental psychiatry, vol. 25, no 1, p. 49-59, 1994.

BRUNER, J. S. Toward a theory of instruction. Harvard University Press, vol. 59, 1966.

CARBAJAL, M. L.; BARANAUSKAS, M. C. C. TaPrEC: Desenvolvendo um ambiente de programação tangível de baixo custo para crianças. Nuevas Ideas en Informática Educativa, vol. 11, p. 363-370, 2015.

CARBAJAL, M. L.; BARANAUSKAS, M. C. C. Evolução de um ambiente para programação tangível e avaliação de seu uso em cenário educacional. Nuevas Ideas en Informática Educativa, vol. 12, p. 666-671, 2016.

NIELSEN, J.; MACK, R. L. Usability inspection methods. New York: Wiley \& Sons, 1994.

MOMBACH, J. G.; MELO, A. M.; WERNZ, M. C. G., DE FREITAS SALDANHA, J.; MACHADO, R. Gurizada.net: inclusão digital em perspectiva participativa. Anais do Workshop de Informática na Escola, p. 1069-1078, 2010.

MULLER, M. J.; HASLWANTER, J. H.; DAYTON, T. Participatory practices in the software lifecycle. Handbook of Human-Computer Interaction (Second Edition), p. 255297, 1997.

SCHULER, D.; NAMIOKA, A. Participatory design: Principles and practices. $C R C$ Press, 1993. 